\title{
Factors affecting Information Systems Security: Field Study
}

\author{
Shahrazad Omar Majid Al Marhoon ${ }^{\# 1}$ \\ Shamma Nasser Mohammed Al Harizi ${ }^{\# 2}$ \\ \# College of Commerce and Business Administration, Department of MIS \\ Dhofar University, Oman
}

\begin{abstract}
The aim of this research is to identify the availability levels of fear, neutralization, and Information Systems Security (ISS) and determining the impacts of Fear, and Neutralization on ISS. The primary data of the study collected using manual distributed questionnaire. By using appropriate statistical test, the collected data has been analyzed. The reliability and hypotheses tested using several statistical methods such as multiple and linear regression test. While validity tested using Cronbach's alpha. The findings of the study shown there is a significant statistical effect of fear and neutralization on the information system security which explains (40.3\%) of the variation in ISS. Also, ISS availability level is high as the mean is (3.49) and the responses are very close as the Standard Deviation is (0.98). the research suggested to Study more variables that may affect ISS and increase restrictive procedures of information security and make sure that everyone in organizations are understand the sequences of violating them.
\end{abstract}

Keywords - fear, neutralization, Information Systems Security.

\section{INTRODUCTION}

Information systems security stay the highest grade of main concerns which information systems administrators faced. Forced entree to storage rooms and computer were most old fears as well as devastation by Natural disasters. However, keeping data and information systems protective from incidental or deliberate illegal access, detection, modification, or demolition are current attention focus. Consequently, these actions can lead to disturbance service to customers which may drove to organization failure [1]-[3]. The breaches to ISS probably at least half of them are made by internal workers, mostly attributed to unlicensed system access. The reduction of incidence of ISS cracks by internal personnel could happen by focus more on internal threats to ISS that can arise when information handled by employees in their daily tasks [4], [5].

The use of information technology (IT) growing speedily by organizations and that has extremely changed assets and critical resources, since they have become digital and consequently transferrable more easily [6], [7]. Therefore, it is essential to warrant that information is not leaked or altered accidentally [8]. The preliminary idea to protect the resources and safeguarding organizations important information of from such threats, is the improvement of information security policy documents that list, for example, appropriate and inappropriate ISS actions for employees [9], [10].

Supposing that ISS policy take place in a work setting, so role values are potentially essential in ISS. The required ISS acts in the ISS rules are viewed as applicable and justified, at what range it is related to the nature of the work the person performs. In addition, role values may be a general reason behind different ISS policy compliance behaviors (or intentions thereof) [11]. However, this study strives to identify to what extent fear, and neutralization may affect Information Systems Security. Therefore, the main goal of this study is to identify the effects of fear, and neutralization on Information Systems Security.

\section{LITERATURE REVIEW}

The theory of neutralization (ToN) suggested by Sykes and Matza (1957) explained the ability of individuals to overcome social standards and other preventive mechanisms and adopt different behaviours[12]. This theory's elementary principle is that reasons justified by people for why they are able to make an exception to a rule, policy, or law, thereby violating the accepted standard [13]. The ToN increases our understanding of ISS research by proposing that people create excuses as rationalizations, through which they rationalize their insecure behaviors to themselves. Neutralization techniques used by Siponen and Vance (2010), and Barlow et al. (2013) to clarify noncompliance (intention) of employee with ISS policies within organizations [11], [13], [14]. 
Boss et al. (2015), and Johnston et al. (2015) reported the significance of the fear element in understanding compliance intentions. Fear has come to ISS through PMT and fear appeals. While fear is studied in health psychology and related to the dodging of health threats[15], lacking fear constructs in the PMT applications is criticizing in ISS research [16]-[18]. Fear makes sense in health psychology, where the threat refers to serious health threats or "noxious medical examination"[15]. However, what is debatable is whether the fear of ISS risks is theoretically the same as the fear of health threat. In the case of our measurements of fear, the measures which not retained are those reflect fear as an emotion, such as terrifying and afraid. Instead, warnings of probable threats were retained as fear. Future research should examine to what extent ISS threats really evoke fear. Could also affect whether ISS threats evoke fear by different types of threats. For instance, that only ISS threats could be viewed as being serious, similar to worries that someone will access one's personal bank account, evoke fear[11].

From a business viewpoint, the classification of insider spying outlines by Maasberg (2014) as an outcome of personal crisis and tendency for interior insurgence which could lead to steal, fraud or vandalism knowledgeable property[19]. In the interdisciplinary study of information systems security and criminology, Siponen and Vance (2010) display techniques of neutralization that employees used to decline the perceived harm of their policy infringements[13]. in the social sciences discipline, Ugrin and Pearson (2010) have conducted experimental studies on the watching and revealing others to pornography and cyber-loafing as a non-compliance form to internal policies of the organization[20]. Warkentin, Malimage, and Malimage (2012) propose in their researches which based on criminology studies that depending on the sorts of negative (punishment), positive (reward) or sanctions present, then through diverse cultures employees might influenced differently by them[21]. Interestingly, Takemura (2014) suggested in his empirical studies in Japanese culture that through the threat of punishment, violating security policy cannot essentially be deterred[22], [23].

According to Whitman (2004), awareness of user is publicized as a strong mechanism to rise compliance and decrease internal wrong using[24]. Bulgurcu et al.(2010) defined information security awareness as a general knowledge of an employee about information security and his or her awareness of the information security policy of the organization[25]. While Siponen (2000) point out, that this definition is steady with the view that security consciousness is a situation in which workers are conscious and are fully dedicated to the security objectives their organizations[26]. According to Kritzinger \& Smith (2008), Information security awareness forms guarantees that all workers are conscious of their role and accountability with respect to information security since it is a part of information security management (Joo \& Hovav, 2016)[27]-[30].

Johnston and Warkentin (2010) used the Fear Appeal Model which explains that behavioural intentions of end user to comply with suggested security acts does effected by fear appeal. Since needs of safety (the need to feel secure and safe, and threats free) high ranked among our needs, through compliance with security procedures, public are expected to sustain a security feeling [26], [31]. However, since users in the future may not completely recognize all probable risks, Web-based IIS might contain greater threats comparing to traditional IS. As the stage of ICT in Peru is quite low, this shortage of awareness is probable to be more significant. Therefore, intention of users to use and adopt the proposed IIS is likely to have a negative effected by perceived security threat [30], [32]-[34].

Researchers and specialists in IS have struggled to problematize violations of IS security and to recommend suitable interventions from several other lenses such as neutralization and rationalization [13], [25]

common IS theories have drawed up Additional experiential studies on security violations which are seen as normative and prescriptive, for instance Motivation [21], [35], Deterrence theory[4], and Protection [23], [36].

To design a reliable security system, a set of security policies, aware staff, procedures, time, effort, and technical and financial resources are required for information security's Implementation. It is conspicuous that the management of the organization's information systems becomes more sophisticated with increased numbers of applications, employees, and systems. To determine secure use of hardware and software, and to facilitate and encourage secure employees' behaviour, organizations utilize ISP[37]. Those policies generate a secured system, if they were accurately planned, implemented, distributed, monitored, refined and supported by senior management[38], [39]. It is significant for the institutions to consider the necessity of setting up criteria of Information Security standards; they should communicate, cooperate and coordinate to implement information security at all institutional levels [40], [41].

\section{RESEARCH MODEL}

Based on the literature the suggested model is presented in figure (1). More, the research suggests the following hypotheses: 


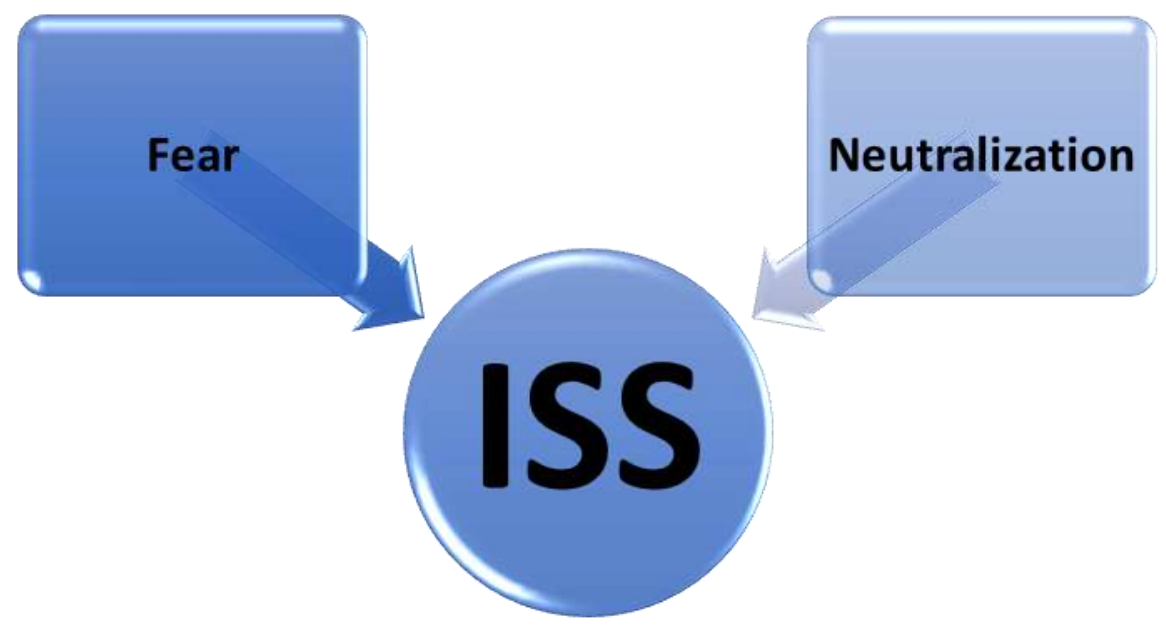

Figure (1): suggested Model

H1: Fear has positive effect on information systems security within the organization.

H2: Neutralization has positive effect on information systems security within the organization.

\section{RESEARCH METHODOLOGY}

A questionnaire-based survey has been distributed manually to collect the primary data about the study variables (fear, and neutralization). However, the study instrument has been prepared based on previously validated models [11], [42]. All the instruction to get the questionnaire filled up has been written on the first page, and confidentiality and privacy has been confirmed. Moreover, five-point Likert scale was adopted ranging from 1 strongly disagree to 5 strongly agree. The final version of the questionnaire was distributed to the targeted staff (100) randomly from higher education institutions in Oman, only 84 questionnaires were returned. A 5 questionnaires were rejected because some have the same answer for all questions in all sections, and many questions left without answers. Therefore, the valid questionnaires for analysis were 79 questionnaires with a rate of $(79 \%)$ which is considered as a good rate in the area of Information Systems. Further, reliability test (Cronbach's Alpha) was used to check the validity of the gathered data which obtained by questionnaire. The results of this aforesaid test, as appears in table (1), confirmed the internal consistency of construct and measures validity. As well as, simple and multiple regression were used for hypotheses test.

\section{Data Analysis}

Table 1 shows the coefficient of alpha Cronbach's which are ranging from $(0.637)$ for neutralization, $(0.729)$ for the fear, and (0.770) for ISS.

Table 1. Descriptive and Reliability Statistics

\begin{tabular}{l|c|c|c|c|}
\hline \multicolumn{2}{c}{} & \multicolumn{2}{c}{ N } & \multicolumn{2}{c}{ Std. Deviation } & Cronbach's Alpha \\
\hline Fear & 79 & 4.3080 & .47072 & .729 \\
\cline { 2 - 5 } $\begin{array}{l}\text { Neutralization } \\
\text { ISS }\end{array}$ & 79 & 3.8734 & 1.09037 & .637 \\
\cline { 2 - 5 } & 79 & 3.4937 & .98219 & .776 \\
\hline
\end{tabular}

Multiple linear regression analysis was conducted with the fear, and neutralization as predictor variables, and ISS as a dependent variable. 
Table 2. Results of regression analysis ${ }^{\text {a }}$

\begin{tabular}{|c|c|c|c|c|c|c|}
\hline & Adjusted $\mathrm{R}^{2}$ & & $\mathrm{~F}$ & \multicolumn{3}{|c|}{ Sig. } \\
\hline \multicolumn{2}{|r|}{.388} & & 25.693 & & \multicolumn{2}{|c|}{$.000^{\mathrm{b}}$} \\
\hline \multicolumn{7}{|c|}{ Dependent Variable: ISS } \\
\hline b. & \multicolumn{6}{|c|}{ Predictors: (Constant), fear, neutralization } \\
\hline \multicolumn{7}{|c|}{ Table 3. the results of hypotheses test ${ }^{a}$} \\
\hline \multicolumn{2}{|r|}{ Suggested Hypotheses } & B & Std. Error & Beta & $\mathrm{t}$ & Sig \\
\hline & H1 & .438 & .086 & .486 & 5.082 & .000 \\
\hline & $\mathrm{H} 2$ & .553 & .200 & .265 & 2.769 & .007 \\
\hline
\end{tabular}

A number of 79 responses have been analyzed. The statistical results presented in Table 2 shows that the entire model was significant $\{\mathrm{F}(2,79)=25.693, \mathrm{P}<0.001\}$ with adjusted $\mathrm{R}^{2}$ being $(0.388)$ which explains only $(38.8 \%)$ of the changes in the ISS. Both constructs fear $(\beta=0.438 ; \mathrm{t}=5.082)$, and neutralization $(\beta=0.553 ; \mathrm{t}=$ 2.769) were significant.

\section{DISCUSSION}

The main objective of this study is to identify the effects of fear and neutralization on ISS. Most of respondents are males and their age ranging between 30 and 50 years, and the majority have an experience more than 10 years. The availability level of fear is high since the mean is (4.31) and the responses of the participators are very close as the standard deviation is $(0.47)$. Also, the availability level of neutralization is high because the mean is (3.87). In addition, ISS availability level is high as the mean is (3.49).

After analysing the data and testing the hypotheses, the study revealed that fear and neutralization have a significant statistical impact on ISS and explains (38.8\%) of the variation in the independent variable. The study found that a lot of respondents have awareness about information system security. Even though there is a need for more focus on other factors and variables witch effect the ISS.

According to the results, the organizations should increase restrictive procedures of information security and make sure that all employees will understand the sequences of violating them and enhancing the background of people about the importance of Information system security to avoid any problems,

\section{CONCLUSION}

Current study aimed to identify the influences of fear and neutralization on ISS. After data analysis and hypotheses testing, the results show that of fear and neutralization has a significant statistical influence on the ISS. In future there is a need to study more variables which may affect the ISS such as trust, and privacy.

\section{REFERENCES}

[1] N. M. M. Al-ahmad Malkawi, M. N. Alraja, and T. Alkhayer, "Information systems auditing applied study at banks listed in the damascus stock exchange Syria," Eur. J. Econ. Financ. Adm. Sci., no. 21, 2010.

[2] K. D. Loch, H. H. Carr, and M. E. Warkentin, “Threats to Information Systems: Today's Reality, Yesterday’s Understanding,” MIS Q., vol. 16, no. 2, p. 173, Jun. 1992.

[3] M. N. Alraja and N. R. Alomian, "THE EFFECT OF INFORMATION TECHNOLOGY IN EMPOWERMENT PUBLIC SECTOR EMPLOYEES: A FIELD STUDY,” Interdiscip. J. Contemp. Res. Bus., vol. 5, no. 1, pp. 805-815, 2013.

[4] D. W. Straub and R. J. Welke, "Coping with Systems Risk: Security Planning Models for Management Decision Making," MIS Q., vol. 22, no. 4, p. 441, Dec. 1998.

[5] J. L. Spears, "A Holistic Risk Analysis Method for Identifying Information Security Risks," in Security Management, Integrity, and Internal Control in Information Systems, Boston: Kluwer Academic Publishers, 2004, pp. 185-202.

[6] A. C. Johnston, M. Warkentin, and M. Siponen, "An Enhanced Fear Appeal Rhetorical Framework: Leveraging Threats to the Human 
Asset Through Sanctioning Rhetoric,” MIS Q., vol. 39, no. 1, pp. 113-134, Jan. 2015.

[7] M. T. Siponen, "Analysis of modern IS security development approaches: towards the next generation of social and adaptable ISS methods," Inf. Organ., vol. 15, no. 4, pp. 339-375, Oct. 2005.

[8] R. Willison and M. Warkentin, "Beyond Deterrence: An Expanded View of Employee Computer Abuse," MIS Q., vol. 37, no. 1, pp. 1-20, Jan. 2013.

[9] R. Baskerville and M. Siponen, "An information security meta- policy for emergent organizations," Logist. Inf. Manag., vol. 15, no. 5/6, pp. 337-346, Dec. 2002.

[10] D. W. Straub, S. E. Goodman, and R. Baskerville, Information security $\square$ : policy, processes, and practices. Routledge, 2015.

[11] G. D. Moody, M. Siponen, and S. Pahnila, "Toward a Unified Model of Information Security Policy Compliance," MIS Q., vol. 42, no. 1, pp. 285-311, Jan. 2018.

[12] G. M. Sykes and D. Matza, "Techniques of Neutralization: A Theory of Delinquency," Am. Sociol. Rev., vol. 22, no. 6, p. 664, Dec. 1957.

[13] M. Siponen and A. Vance, "Neutralization: New Insights into the Problem of Employee Information Systems Security Policy Violations," MIS Q., vol. 34, no. 3, p. 487, 2010.

[14] J. B. Barlow, M. Warkentin, D. Ormond, and A. R. Dennis, "Don’t make excuses! Discouraging neutralization to reduce IT policy violation," Comput. Secur., vol. 39, pp. 145-159, Nov. 2013.

[15] R. Rogers, R. W. ROGERS, R. Rogers, and R. W. Rogers, "Cognitive and physiological process in fear appeals and attitudes changer: A revised theory of protection motivation,” Soc. Psychophysiol., pp. 153-176, Jan. 1983.

[16] M. N. Alraja and M. A. Kashoob, "Transformation to electronic purchasing: an empirical investigation," TELKOMNIKA (Telecommunication Comput. Electron. Control., vol. 17, no. 3, pp. 1209-1219, Jun. 2019.

[17] S. R. Boss, D. F. Galletta, P. B. Lowry, G. D. Moody, and P. Polak, "What Do Systems Users Have to Fear? Using Fear Appeals to Engender Threats and Fear that Motivate Protective Security Behaviors," MIS Q., vol. 39, no. 4, pp. 837-864, Apr. 2015.

[18] M. N. Alraja, "The effect of social influence and facilitating conditions on e-government acceptance from the individual employees' perspective | Efekt Wpływu Społecznego Oraz Warunków Ułatwiających Akceptację E-Administracji Z Punktu Widzenia Indywidualnych Pracowników," Polish J. Manag. Stud., vol. 14, no. 2, 2016.

[19] M. Maasberg, "Insider Espionage: Recognizing Ritualistic Behavior by Abstracting Technical Indicators from Past Cases," in Twentieth Americas Conference on Information Systems, 2014, pp. 1-10.

[20] J. Ugrin and J. Pearson, "UNDERSTANDING THE EFFECT OF DETERRENCE MECHANISMS ON CYBERLOAFING: EXPLORING A GENERAL DETERRENCE MODEL WITH A SOCIAL PERSPECTIVE,”ICIS 2010 Proc., Jan. 2010.

[21] M. Warkentin, N. Malimage, and K. Malimage, “Association for Information Systems AIS Electronic Library (AISeL) Impact of Protection Motivation and Deterrence on IS Security Policy Compliance: A Multi-Cultural View Recommended Citation \&quot;Impact of Protection Motivation and Deterrence on IS Security Policy Compliance: A Multi-Cultural View\&quot;," 2012.

[22] T. Takemura, "Empirical analysis of intentional security policy violation in the workplace," Econ. Rev., vol. 46, no. 6, pp. 21-40, 2014.

[23] A. Bhattacherjee, "Understanding Information Systems Continuance: An Expectation-Confirmation Model," MIS Q., vol. 25, no. 3, p. 351, Sep. 2001.

[24] M. E. Whitman and M. E., "In defense of the realm: understanding the threats to information security," Int. J. Inf. Manage., vol. 24, no. 1, pp. 43-57, Feb. 2004.

[25] B. Bulgurcu, H. Cavusoglu, and I. Benbasat, "Information security policy compliance: An empirical study of rationality-based beliefs and information security awareness," MIS $Q$., vol. 34, no. 3, 2010.

[26] M. T. Siponen, "A conceptual foundation for organizational information security awareness," Inf. Manag. Comput. Secur., vol. 8, no. 1, pp. 31-41, Mar. 2000.

[27] M. N. Alraja and N. M. M. Malkawi, "E-Business Adoption in Banking Sector: Empirical Study," Indian J. Sci. Technol., vol. 8, no. 27, Oct. 2015.

[28] E. Kritzinger and E. Smith, "Information security management $\square$ : an information security retrieval and awareness model for industry," 2008.

[29] M. A. Hussein, H. M. S. Ahmed, and M. N. Alraja, "The adoption of information and communication technology by small and medium enterprises in Oman: Case of Dhofar region,” J. Bus. Retail Manag. Res., vol. 11, no. 3, pp. 64-71, 2017.

[30] J. Joo and A. Hovav, "The influence of information security on the adoption of web-based integrated information systems: an e- 
government study in Peru,” Inf. Technol. Dev., vol. 22, no. 1, pp. 94-116, Jan. 2016.

[31] M. N. Alraja, B. F. Salim, M. A. Uddin, and M. Yousoof, “The adoption of internet banking: Clients' perspective in Oman," Int. Rev. Manag. Mark., vol. 6, no. 4, 2016.

[32] M. N. ALraja and M. Aref, "Customer acceptance of e-commerce: Integrating Perceived Risk with TAM,” Int. J. Appl. Bus. Econ. Res., vol. 13, no. 2, 2015.

[33] M. A. Uddin, F. Ahmar, and M. N. Alraja, "E-examinations for management students in Oman," Int. J. Appl. Bus. Econ. Res., vol. 14, no. $1,2016$.

[34] M. N. Alraja, "User Acceptance of Information Technology: A Field Study of an E-Mail System Adoption from the Individual Students' Perspective,” Mediterr. J. Soc. Sci., vol. 6, no. 6 s1, pp. 19-25, Nov. 2015.

[35] F. M. Alkhaldi, S. M. Hammami, S. Kasem, A. Rashed, and M. N. Alraja, "Enterprise System as Business Intelligence and Knowledge Capabilities for Enhancing Applications and Practices of IT Governance,” Int. J. Organ. Collect. Intell., vol. 7, no. 2, pp. 63-77, 2017.

[36] M. A. A. Rasheed and M. N. Alraja, "Data mining approach to assess condition of rotating machine using sound signal," J. Theor. Appl. Inf. Technol., vol. 80, no. 1, 2015.

[37] M. Al-Awadi and K. Renaud, "SUCCESS FACTORS IN INFORMATION SECURITY IMPLEMENTATION IN ORGANIZATIONS," IADIS Int. Conf. e-Society.

[38] M. N. ALraja and B. Chikhi, "Perceived factors affecting customers attitudes toward electronic shopping: An empirical study," Int. J. Econ. Res., vol. 12, no. 3, 2015.

[39] S. Al Harizi and S. O. Al Marhoon, "Factors Affecting the Adoption of E-Commerce: An Evidence from Developing Country," Int. J. Sci. Manag. Stud., vol. 2, no. 3, pp. 86-90, 2019.

[40] S. Hammami, M. N. Alraja, and S. A. Jamil, "The role of it in enhancing productivity at higher education institutions from staff and students' Perspective-evidence from Oman,” J. Theor. Appl. Inf. Technol., vol. 80, no. 3, 2015.

[41] A. S. Brima and B. Sesay, "Barriers to E-Commerce Adoption among SMEs in Sierra Leone: The Moderating Role of Geographical Location,” Int. J. Sci. Manag. Stud., vol. 2, no. 1, pp. 1-12, 2019.

[42] M. N. Alraja, M. M. J. Farooque, and B. Khashab, “The Effect of Security, Privacy, Familiarity and Trust on Users' Attitudes Towards the Use of IoT-based Healthcare: The Mediation Role of RiskPerception,” IEEE Access, vol. 7, pp. 1-1, 2019. 